Original article

\title{
Epidemiological study on pediatric unilateral cochlear implantation in Gujarat, India: Discrepancy among children based on age of implantation, gender, region and type of implant device as per manufacturers
}

\author{
Anuj Kumar Neupane*, Gunjan Mehta \\ Department of Audiology and Speech Therapy, C.U. Shah Medical College and Hospital, Surendranagar, 363001, Gujarat, India
}

\section{A R T I C L E I N F O}

\section{Keywords:}

Prevalence

Hearing loss

Pediatric

Cochlear implant

Gujarat

\begin{abstract}
A B S T R A C T
Background: To overcome the hazardous effect of hearing loss, bioelectrical intensive research over the last five decades has advanced with invasive hearing devices, cochlear implants. The epidemiological study on the number of cochlear implantation performed across the world is rare.

Objectives: The present study aimed at estimating the prevalence of unilateral cochlear implantation in children in the Saurashtra region, Gujarat between the month of December, 2013 and August, 2019.

Materials and Methods: A register-based, retrospective study was employed reviewing the clinical reports of the cochlear implantees on age at implantation, gender, region of belonging and the type of implant device being used.

Results: 216 children underwent cochlear implantation at the Saurashtra region under School Health Programme. The total study population constituted 61\% (132) male and 39\% (84) female implantees. Higher number of implantations were performed with Cochlear device at later childhood (6-7 years of age) and most of the implantees were from the Saurashtra region of Gujarat as compared to other regions.

Conclusion: The present study speculated that the differences in age at implantation, gender, region of belonging and the type of implant being used based on the manufacturer. The results of the present study could be used to plan and execute policies for the identification, management, and rehabilitation of individuals with hearing impairment.
\end{abstract}

\section{Background}

Hearing impairment is the most common sensory deficit, affecting the excess number of individuals around the globe. ${ }^{1}$ Consequences of hearing impairment lead to inability in understanding speech signals decreased capability to converse, delay in the development of language skills, educational and economic backwardness, social seclusion and stigmatization. ${ }^{2} 360$ million individuals suffer from hearing impairment worldwide that comprise a considerable $5.3 \%$ of the total world's population. Hearing loss has an adverse effect on different aspects of auditory functioning which includes detection, discrimination, and resolution and noise avoidance. These deficits lead to the difficulty in speech perception and production which gets exacerbated in the presence of noise. Reduced hearing and communication ability have a strong association with depression and functional decline, contributing to the degraded quality of life. ${ }^{2,3}$ The vital aim of aural rehabilitation is to reduce deficits induced by hearing impairment, therefore, resulting in degraded quality of life. Aural rehabilitation with various hearing assistive devices enhances auditory function which further augments speech perception skills. ${ }^{4}$

Attempts to provide hearing by electrical stimulation of the auditory system have a long history going back around late 18th century with the discovery of the electrolytic cell. ${ }^{5}$ The bioelectrical intensive research over the last five decades has advanced with invasive hearing devices, cochlear implants. ${ }^{6}$ Cochlear implants are surgically implanted neuro-prosthetic devices that give the sensation of hearing in individuals with irreversible sensorineural hearing loss. These implants bypass the normal acoustic hearing process instead replacing it with electric signal which directly stimulates auditory nerve. ${ }^{7}$ The epidemiological study on the number of cochlear implantation performed across the world is rare. Few studies have attempted to assess the impact of implant technology reaching various sectors of the society based on the degree of hearing loss, age, gender, race, and ethnicity, therefore, helping in the formulation and implementation of apt policies to

\footnotetext{
* Corresponding author. Bharati Vidyapeeth School of Audiology and Speech language pathology, India.

E-mail address: anujkneupane@gmail.com (A.K. Neupane).
} 
reduce the barrier if any. ${ }^{8-10}$

A database study by Stern et al. ${ }^{8}$ reported 124 children (mean age of 5 years) who underwent cochlear implantation where all of them were medically insured. $61 \%$ of the study population was male. Most of the cochlear implantees were white and Asian pediatric patients than black and Hispanic patients. It was found to have a higher concentration of pediatric cochlear implantees residing in wealthier regions. Another database study by Chang et al. ${ }^{10}$ reported the need to create awareness regarding good hygiene, periodic follow-up and sequential bilateral implantations in individuals undergoing cochlear implantation. The total number of 133 pediatric patients underwent cochlear implantation during the period 1996 to 2008 at Cleveland, Ohio, where all of them were medically insured. The study revealed the importance of adequate reimbursement for equal access to the cochlear implantation irrespective of socio-economic status. The study by De Raeve et al. ${ }^{9}$ suggested a considerable variation in CI utilization within Europe because of underutilization of implantations, especially in adults. The prevalence of 200 cochlear implantees per million individuals in Western European countries and 50-75 implantees per million in Eastern European countries were reported. The difference in the number of implantees was related to the provision of limited funding in Eastern Europe than its western counterpart. Also, the cochlear implantation got initiated earlier in Western European countries as compared to the Eastern side. Reimbursement guidelines could be the other reason for such a difference in the ratio of several pediatric versus adult implantees. Most of the European countries reimburse the amount of implantation in children and not in adults leading to the disparity mentioned above. Thus, it was mentioned regarding the need for awareness about the importance of implants in improvising the quality of life-based on costeffectiveness data and guidelines for good clinical practice.

Even though the extensive studies on the prevalence of cochlear implantation have been performed in the western world, there has been always a lacuna in the South Asian region with a higher prevalence of deafness. ${ }^{1}$ Huge burden of hearing impairment across the world and in India is largely avoidable. The incidence and prevalence and of hearing impairment in India are significantly elevated where 21 per 1000 children have hearing impairment. ${ }^{11}$ To eliminate hearing-loss induced deficits, cochlear implantation can be a reliable option which is a relatively new entrant in India. Though the implants have existed in India for long, the usage has been limited because of the high costs. Apart from the cost of the surgery, one has to add the costs of 1-2 years' intensive speech therapy for the child to associate various sounds and learn speech. ${ }^{12}$ As a result, the union government, as well as the state governments of India, has initiated various schemes and programs to assist the children with severe to profound hearing impairment in procuring cochlear implantation for promoting their communication and psychological needs. ${ }^{13}$ One such scheme, School Health Program, has been running in the state of Gujarat where the overall prevalence of communication disorder is $4.09 \%$ with otological disorders ranked highest (3.30\%). ${ }^{14}$ The average age of suspicion about hearing loss in the state is reported to be $2.9 \pm 1.7$ years, with the first consultation done at $3.5 \pm 1.5$ years and the age of intervention performed at $7.8 \pm 3.3$ years. $^{15}$ Therefore, under School Health programme, the state government has been attempting to intervene individuals with profound hearing loss with free cochlear implantation and rehabilitation at various government hospitals since $2013 .{ }^{16}$ However, the prevalence of cochlear implantation under the program across the state of Gujarat has never been studied which could give insight on the impact of the programme at the public level. Also, the study based on the age at implantation, gender, region of belonging across Gujarat and implant device being used by the cochlear implantees since the initiation of program could trace the importance in understanding the efficacy of the program at various levels.

Therefore, the present study aimed at estimating the prevalence of unilateral cochlear implantation in children based on their age at implantation, gender, region of belonging and implant device being used under the School Health Program at various government hospitals of Saurashtra region, Gujarat between the months of December, 2013 and August, 2019.

\section{Methodology}

A register-based, retrospective study was employed wherein purposive sampling was done and fully nested sampling matrix was utilized to review the clinical reports of the cochlear implantees who underwent surgery at cochlear implant centers at different government hospitals of Saurashtra region, Gujarat under the School Health Program between the months of December, 2013 and August, 2019. During this period, the total sample of 216 children between the ages of 6 months till 6 years 11 months was considered. Details based on case histories such as age at implantation, gender, region of belonging and the type of implant device used based on manufacturer were documented. In the study, children between the age ranges of 6 years till 6 years 11 months were considered as the age group of 6-7 years. All the children were reported to have congenital hearing loss with no other disabilities mentioned. With this information collected, the data analysis was done to understand the prevalence of pediatric unilateral cochlear implantation performed in the region.

\section{Results}

The total study population constituted 61\% (132) male and $39 \%$ (84) female implantees varying across different age groups, the region of belonging across Gujarat and implant device being used. The details of the cochlear implantation performed at the given period are given in Table 1.

The cochlear implant population varied across the age at implantation. It was found that $6 \%$ (male $=9$ and female $=3$ ) of the recipients got implanted below the age of 2 years, $14 \%$ (male $=17$ and female $=14$ ) between the age of $2-3 y e a r s, 25 \%$ (male $=28$ and female $=25$ ) between the age of $3-4$ years, $17 \%$ (male $=24$ and female $=13$ ) between the age of $4-5$ years, $16 \%$ (male $=19$ and female $=15$ ) between the age of 5-6years and $22 \%$ (male $=35$ and female $=14$ ) between the age of 6-7years as given in Fig. 1 .

It can be seen from Fig. 1 that the number of cochlear implantees was higher in the later stage of childhood at around 6-7 years of age than below 2 years of age. Also, it can be seen that the male cochlear implantees were higher in number as compared to the females. Pearson's Chi square revealed significant gender difference between the cochlear implantees $\left[\chi^{2}(1)=10.67, \mathrm{p}<0.05\right]$. Also, it revealed significant difference across age of implantation $\left[\chi^{2}(5)=29.6, \mathrm{p}<0.05\right]$. However, it revealed no significant association of age at implantation

Table 1

Detailed data demonstrating the total number of children undergoing cochlear implantation varying across age at implantation, gender, region of belonging and implant device being used between the years 2013 and 2019.

\begin{tabular}{|c|c|c|c|c|c|}
\hline \multicolumn{3}{|c|}{ Variables } & \multicolumn{2}{|c|}{ Gender } & \multirow[t]{2}{*}{ Total } \\
\hline & & & Male & Female & \\
\hline \multirow[t]{6}{*}{1} & Age at Implantation & $<2$ years & 9 & 3 & 12 \\
\hline & & 2-3years & 17 & 14 & 31 \\
\hline & & 3-4years & 28 & 25 & 53 \\
\hline & & 4-5years & 24 & 13 & 37 \\
\hline & & 5-6years & 19 & 15 & 34 \\
\hline & & 6-7years & 35 & 14 & 49 \\
\hline \multirow[t]{5}{*}{2} & Region of Belonging & Saurashtra & 98 & 60 & 158 \\
\hline & & Central & 13 & 9 & 22 \\
\hline & & North & 12 & 8 & 20 \\
\hline & & South & 4 & 3 & 7 \\
\hline & & Kutch & 5 & 4 & 9 \\
\hline \multirow[t]{2}{*}{3} & Implant device being used & Cochlear & 117 & 72 & 189 \\
\hline & & Medel & 15 & 12 & 27 \\
\hline
\end{tabular}




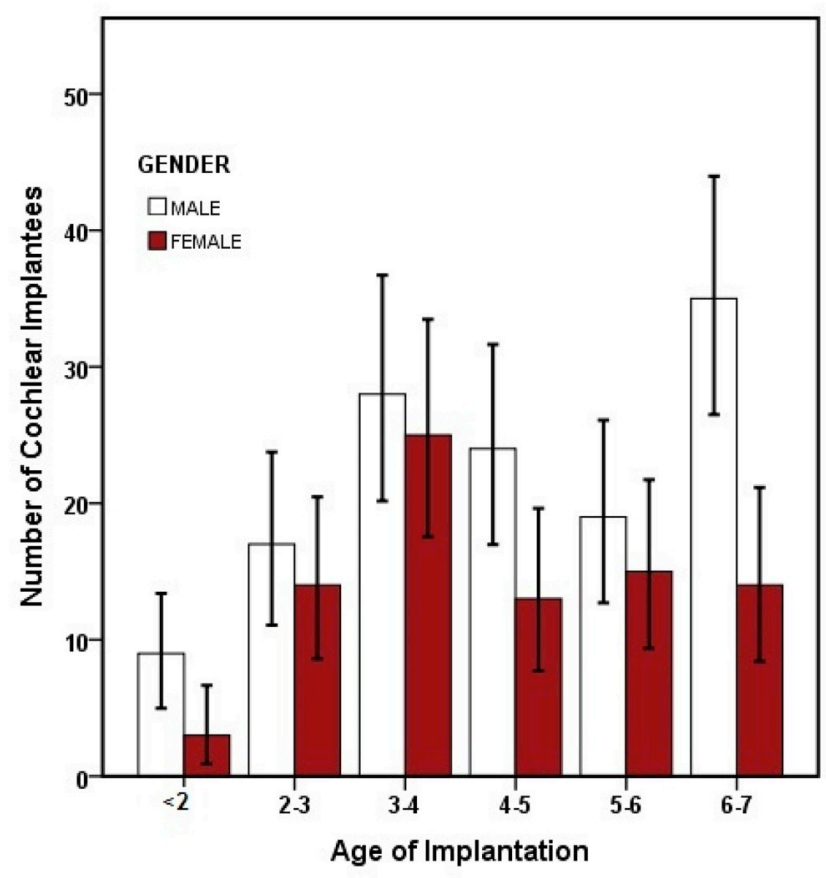

Fig. 1. Total number of cochlear implantees across age at implantation and gender between December, 2013 and August, 2019.

with the gender $\left[\chi^{2}(5)=5.82, \mathrm{p}>0.05\right]$.

School Health Program has been conducting free cochlear implantation for children till the age of 6 years 11 months across all six regions of Gujarat. Hence, even if the surgery was performed at the Saurashtra region, Gujarat, the data was analyzed to understand the region of belongings of these cochlear implantees as shown in Fig. 2.

It could be traced from Fig. 2 that $73 \%$ (male $=98$ and female $=60$ ) of the implantees were from Saurashtra region, $10 \%$ (male $=13$ and female $=9$ ) from Central Gujarat, 9\% (male $=12$ and

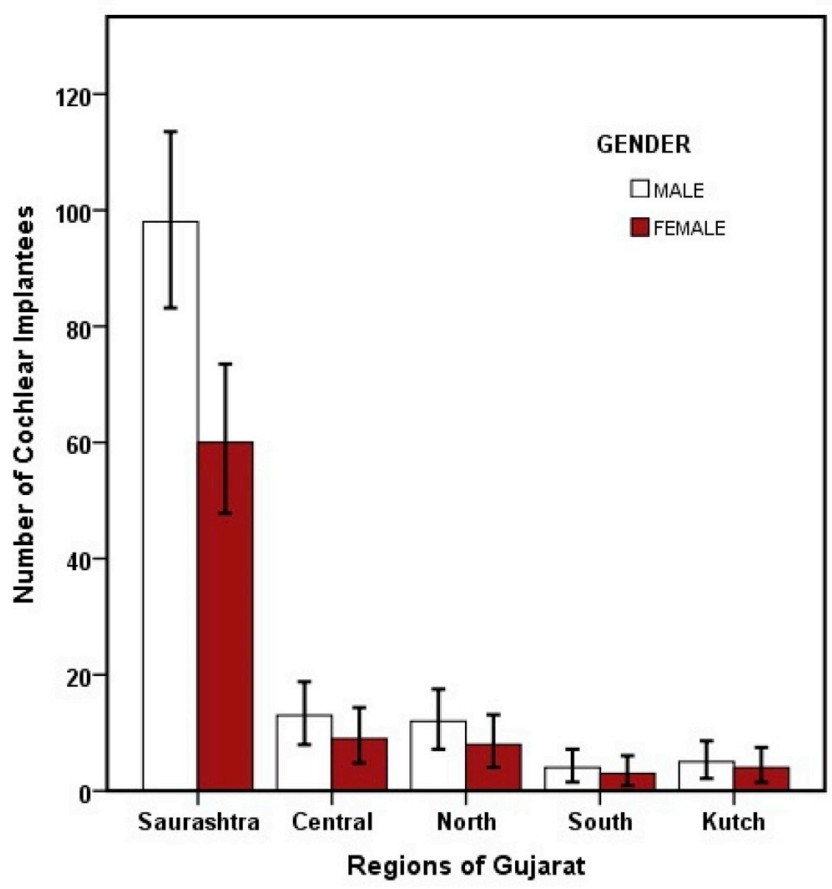

Fig. 2. Total number of cochlear implantees across the region of belongings and gender between December, 2013 and August, 2019.

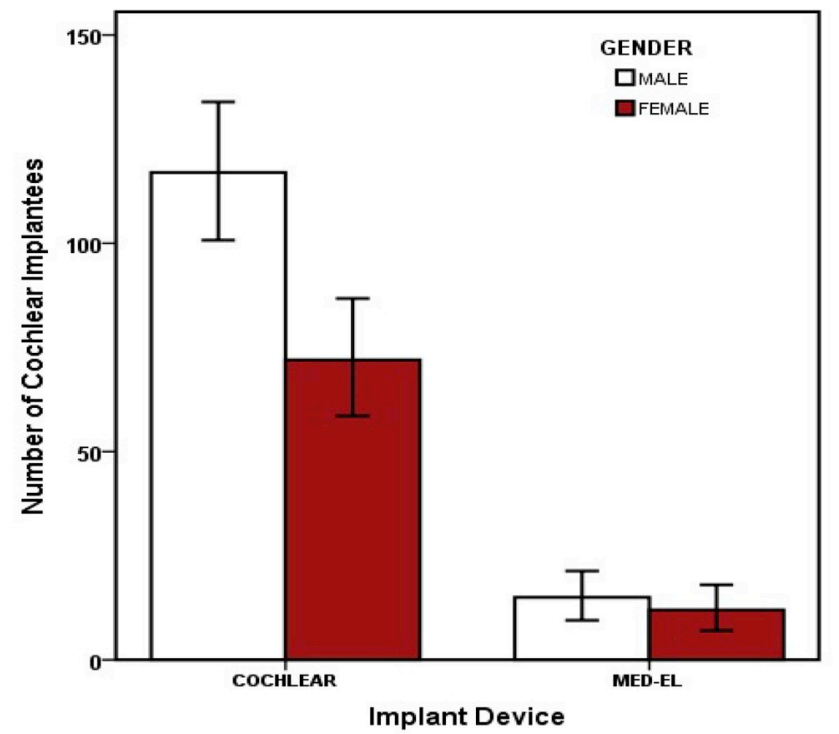

Fig. 3. Total number of different implants devices based on manufacturer, being used by cochlear implantees between December, 2013 and August, 2019.

female $=8$ ) from North Gujarat, $3 \%$ (male $=4$ and female $=3$ ) from South Gujarat and 4\% (male $=5$ and female $=4$ ) from Kutch who underwent cochlear implantations at government hospitals at Saurashtra region. Pearson's Chi square revealed significant difference in the number of implantees across the region of belonging $\left[\chi^{2}(4)=385.3\right.$, $\mathrm{p}<0.05]$. However, no significant association of region of belonging and the gender was found $\left[\chi^{2}(4)=0.27, p>0.05\right]$.

Over the period between 2013 and 2019, different implant manufacturers have been providing the service under the program. Hence, the attempt was made to understand the number of different implant devices being used by the implantees as given in Fig. 3 .

It can be seen in Fig. 3 that $88 \%$ (male $=117$ and female $=72$ ) of the children were implanted with Cochlear Nucleus device and only $12 \%$ (male $=15$ and female $=12$ ) of them were implanted with MEDEL device between the year 2013 and 2019. There was found to have significant difference in the amount of the implant device based on the manufacturers $\left[\chi^{2}(1)=121.1, p<0.05\right]$. However, it revealed no significant association between implant device based on manufacturer and the gender $\left[\chi^{2}(1)=0.41, \mathrm{p}>0.05\right]$.

\section{Discussion}

In the present study, out of 216 children who underwent cochlear implantation at various hospitals of the region under the School Health Program, 61\% (132) were boys and 39\% (84) were girls and there was significant difference across gender. This result is in coherence with the study by Sinha et al. ${ }^{14}$ where the prevalence of otological conditions was relatively higher in males $(1.66 \%)$ than compared to females $(1.63 \%)$ in the state of Gujarat. Similarly, the study by Patel et al. ${ }^{15}$ reported a total of 246 hearing-impaired children with a male: female ratio of 1.7:1. Also, the National Sample Survey Office (NSSO) ${ }^{11}$ report suggested the prevalence of hearing loss in males to be higher than female and it was in coherence with the population ratio of 918 females per 1000 males in the state of Gujarat. ${ }^{17}$ Therefore, these findings advocate the result in the present study where a comparatively higher number of male candidates underwent implantation as compared to females.

Also, the age at implantation was studied where it was found to have significant difference as the relatively higher number of implantations were seen in later stages of childhood than performed earlier. Maximum implantation (22\%) was performed at the age of 6-7 years as compared to only $6 \%$ implantations at the age of fewer than 2 
years. It could be seen that the majority of these children are getting implanted post the critical age of language learning which might affect the prognosis of the condition. This could trace on the key issue in implementing early diagnosis and intervention programs effectively as it can obviate communication disorder by $40 \%$ of the population. ${ }^{13}$ The study by Patel et al. ${ }^{15}$ reported 1 in 5 children not aware of their hearing loss and its impact on daily living. This could be due to the concern given only to the visible ear anomalies and ear discharge and not to the hearing loss by parents in initial days of childhood. Late implantation in the present study can be attributed to the various reasons such as inaccessibility of health facilities for those who were outside the catchment area, parental indecision due to the lack of awareness and medical complexities/additional disabilities resulting in considerable time required to address the uncertainties by parents and cochlear implant team.

In the present study, there was significant difference found among the implantees and their region of belonging. Even though, the children from all over Gujarat were implanted, the majority of them, i. e, 73\% (158) were from the Saurashtra region followed by other regions with the least of $4 \%$ (9) from Kutch region. As per the census, ${ }^{17}$ Gujarat is less variable in terms of demography and literacy rate across its five regions. However, the present result can be attributed to the ease of accessibility of health facilities for children within the Saurashtra region in comparison to other regions of Gujarat. In the study, 10\% (22) of children were from Central Gujarat which might attribute to the fact of the close proximity of the respective region to the Saurashtra region. Hence, this suggests the need for easy access to health facilities for early assessment and intervention of communication disorders effectively.

As it was epidemiological based study, the attempt was made to understand the number of implantees based on the type of implant by manufacturers. This information could be of greater importance for further studies in understanding the effect of implantation in these children as well as understanding the servicing provided for the specific devices in future. In the present study, it was found to have significant difference in the amount of the implant device based on the manufacturers. Majority of $88 \%$ (189) children were implanted with Cochlear Nucleus device and only $12 \%$ (27) of them were implanted with MED-EL device. The result could be attributed to the fact that different implant manufacturers were providing service under the School Health Program at different periods. Initially, the tender for the provision of implant device was given to MED-EL company from 2013 till 2016. Fewer implantations were performed during this period which might be attributed to the poor level of awareness regarding the hearing loss and cochlear implantation among public in the state of Gujarat. ${ }^{14}$ Over the period of time, with ongoing cochlear implant surgeries and therefore, increased awareness across population, the number of implantations could be seen increased. Hence, the majority of implantees since 2016 onwards might be coincidental as the tender for implant device provision was given to Cochlear limited by the government of Gujarat.

\section{Conclusions}

Hence, the present study speculates that the differences in age at implantation, gender, region of belonging and the type of implant being used based on the manufacturer. This information could be used to develop a database, which could include information from different regions of Gujarat and across the country. This would help in better understanding the prevalence of cochlear implantation across the different regions in creating awareness regarding the good hygiene, periodic follow-up and sequential bilateral implantations in individuals undergoing cochlear implantation. The results of the present study could be used to plan and execute policies for the identification, management, and rehabilitation of individuals with hearing impairment. In the present study, information bias could be taken as the limitation of the study where aspects such as socio-economic status and educational status of the children and families are unavailable due to technical restrictions. Also, the entire cochlear implantees' population of Gujarat could not be covered, which would have given a better estimate of the prevalence. It is recommended that further studies of the kind may be carried out to provide the entire information.

\section{Financial support and sponsorship}

This research did not receive any specific grant from funding agencies in the public, commercial, or not-for-profit sectors.

\section{Declaration of competing interest}

None.

\section{References}

1. World Health Organization. Deafness and hearing impairment - fact sheet. . March, Available from: https://www.who.int/news-room/fact-sheets/detail/deafness-andhearing-loss; 2019.

2. Mulrow CD, Aguilar C, Endicott JE, et al. Association between hearing impairment and the quality of life of elderly individuals. J Am Geriatr Soc. 1990;38:45-50.

3. Appollonio I, Carabellese C, Frattola L, Trabucchi M. Effects of sensory aids on the quality of life and mortality of elderly people: a multivariate analysis. Age Ageing. 1996;25:89-96.

4. Maki-Torkko EM, Brorsson B, Davis. A Hearing impairment among adults—extent of the problem and scientific evidence on the outcome of hearing aid rehabilitation. Scand J Audiol Suppl. 2001:8-15.

5. McCormick B, Archbold S. Cochlear Implants for Young Children. second ed. London (UK): Whurr Publishers Ltd.; 2003.

6. Clark G. Cochlear Implants Fundamentals \& Applications. Melbourne: AIP Press Springer; 2003.

7. Clark G. Cochlear Implants. InSpeech Processing in the Auditory System 2004 (pp. 422-462). Springer, New York, NY.

8. Stern RE, Yueh B, Lewis C, Norton S, Sie KC. Recent epidemiology of pediatric cochlear implantation in the United States: disparity among children of different ethnicity and socioeconomic status. Laryngoscope. 2005 Jan;115(1):125-131.

9. De Raeve L, van Hardeveld R. Prevalence of cochlear implants in Europe: what do we know and what can we expect. J Hear Sci. 2014;3(4):9-19.

10. Chang DT, Ko AB, Murray GS, Arnold JE, Megerian CA. Lack of financial barriers to pediatric cochlear implantation: impact of socioeconomic status on access and outcomes. Arch Otolaryngol Head Neck Surg. 2010 Jul 19;136(7):648-657.

11. National Sample Survey Organization (NSSO) Report. Disabled Persons in India 2002; 2002 Report No. 485, 58/26/1.

12. Garg S, Singh R, Chadha S, Agarwal AK. Cochlear implantation in India: a public health perspective. Indian J Med Sci. 2011;65:116-120.

13. Kumar RN, Kameswaran MO. Cochlear implantation in the developing world: perspectives from the Indian subcontinent. ENT Audiol News. 2017;26(4):88-89.

14. Sinha SK, Shivaswamy J, Barman A, Seth D, Seshadri D, Savithri S. Prevalence of communication disorders in a rural population at taluq level of Gujarat, India. Clin Epidemiol Glob Health. 2017;5:73-78.

15. Patel HC, Moitra M, Modi A, Contractor J, Kantharia SL. Impact of hearing loss on daily life style and schooling among children between 5 and 15 years age-group. Natl. J Community Med. 2014;5(1):73-76.

16. National Health Mission. . Available from: https://nrhm.gujarat.gov.in/rbsk.html; 2019.

17. Census. (Final Data) - Demographic Details, Literate Population (Total, Rural \& Urban)" (PDF). Planningcommission.gov.in. Planning Commission, Government of India; 2011 Archived (PDF) from the original on 27 January 2018. , Accessed date: 3 October 2018. 